\title{
ALAT UKUR INDUKTANSI DIGITAL BERBASIS ATMEGA 32
}

\author{
Hanna Fury Nur Ramdany, Heru Winarno \\ Program Studi Diploma III Teknik Elektro \\ Sekolah Vokasi Universitas Diponegoro
}

\begin{abstract}
Hanna Fury Nur Ramdany, Heru Winarno in this paper explain that inductors have an important role in the field of electronics. Many values of capacitors and inductors whose values are difficult to translate, namely when capacitors and inductors are of low value and the color of the print is less clear, also considering the human read factor when an analog measuring instrument is used. From these problems, it is designed an inductance measuring instrument (L Meter) whose results can be directly displayed.

The research method used in the manufacture of inductance meter measuring instruments is the literature method and laboratory tests using frequency variables generated or read by the oscillator circuit. The inductance measuring instrument designed in this researc is simple and meticulous measuring instrument that can be read and used by everyone. This digital inductance meter can be used to measure inductance - inductance with a level or a range of measurements between $20 \mu \mathrm{H}-100 \mathrm{mH}$.

The lower the inductor value measured, the higher the percentage error. So that the tools designed must be able to work well. The average error ratio of an inductance meter with a standard LCR meter is $6.5 \%$. .
\end{abstract}

Keywords: Measuring, Inductor, Microcontroller and LCD Display

\section{PENDAHULUAN}

Dengan semakin majunya perkembangan di bidang tekhnologi elektonika maka kebutuhan akan alat elektronik menjadi semakin meningkat dan ketergantungan manusia terhadap alat elektronik tersebut juga semakin besar. Dalam rangkaian elektronika terdapat bermacam - macam komponen dasar penyusunnya. Seperti resistor, induktor, kapasitor dan lain sebagainya. Sudah banyak alat ukur yang dapat mengukur nilai dari suatu komponen seperti nilai ohmmeter, induktansimeter,maupun kapasitansimeter dan lain-lain.

Biasanya alat ukur ini dibuat dalam suatu instrument yang disebut dengan RLC meter. Alat ini merupakan alat yang dapat berbentuk konvensional atau dapat berbentuk digital. Akan tetapi alat ukur

\section{LANDASAN TEORI Induktor}

Benda fisik yang ciri utamanya adalah induktansi disebut induktor. Induktor adalah unsur penyimpan tenaga dalam bentuk medan magnet dan akan melepaskembali ke rangkaian bila sumber yang mengisinya tidak ada lagi.

Arus dalam induktor tidak bergantung pada nilai sesaat tegangannya, melainkan pada nilai sejak awal hingga saat tegangan diamati, yaitu integral atau jumlah hasil kali volt-detik untuk seluruh waktu hingga saat diamati. Jika diinginkan untuk mengetahui arus induktor yang mengikuti peristiwa pengalihan yang biasannya terjadi pada sebarang saat.
$R L C$ meter yang berbentuk digital harganya relatif sangat mahal.

Pengukuran induktansi suatu induktor sangat diperlukan. Hal ini dikarenakan fungsi induktor sebagai komponen dasar elektronika memiliki peranan yang penting. Antara lain diaplikasikan dalam rangkaian elektronika yaitu untuk memilih frekuensi pada radio penerima, meratakan fluktuasi tegangan dan sebagainya. Banyak nilai induktor yang nilainya sulit diterjemahkan yaitu ketika induktor bernilai kecil dan memiliki warna cetak yang kurang jelas. Dari permasalahan yang ada maka dirancang alat ukur induktansi digital yang berbasis mikrokontroller dengan menggunakan $L C D$ sebagai tampilannya agar memperoleh nilai induktansi yang lebih spesifik, dimana ketelitian dan range pengukuran dapat direncanakan.

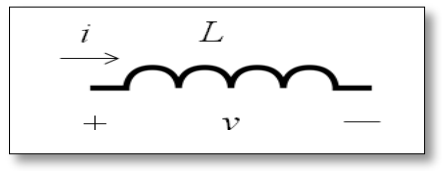

Gambar 1. Lambang Rangkaian Induktansi

\section{Catu Daya}

Arus Listrik yang kita gunakan di rumah, kantor dan pabrik pada umumnya adalah dibangkitkan, dikirim dan didistribusikan ke tempat masing-masing dalam bentuk arus bolak-balik atau arus AC (Alternating Current). Hal ini dikarenakan pembangkitan dan pendistribusian arus listrik melalui bentuk arus bolak-balik $A C$ merupakan cara yang paling ekonomis dibandingkan dalam bentuk arus searah atau arus DC (Direct Current). 


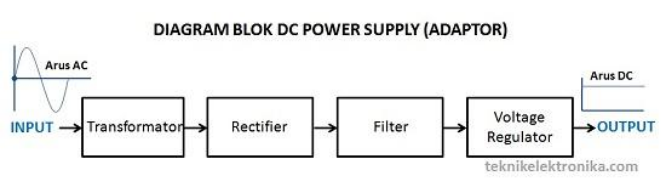

Gambar 2.Diagram Power Supply

\section{Baterai 3.7 V}

Baterai yang digunakan merupakan baterai isi ulang (rechargeable) 3.7V $6800 \mathrm{mAh}$. Baterai ini merupkan baterai Lithium-Ion yang dapat dicharge kembali menggunakan charger dengan tegangan yang sama dengan baterai tersebut. Cara kerja dari baterai dapat menghasilkan energi ini adalah dengan reaksi kimia yang ada di dalam kotak baterai .

\section{Regulator LM 7805}

Regulator berfungsi untuk mengatur kestabilan arus yang mengalir ke rangkaian elektronika. Seri LM78XX (dengan XX=05, 06, 08, 10, 12, 15, 18, atau 24) adalah regulator tegangan tiga terminal tipikal. 7805 menghasilkan keluaran $+5 \mathrm{~V}, 7806$ menghasilkan $+6 \mathrm{~V}, 7808$ menghasilkan $+8 \mathrm{~V}$, dan seterusnya sampai 7824 menhasilkan keluaran $+24 \mathrm{~V}$.

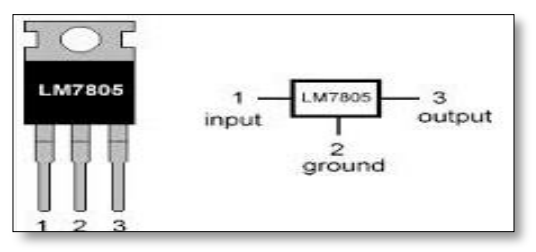

Gambar 3. Susunan Kaki IC Regulator 7805

\section{Osilator}

\section{Osilator LC}

Osilator relaksasi merespon piranti elektronik dimana akan bekerja pada selang waktu tertentu kemudian mati untuk periode waktu tertentu. Kondisi pengoperasian ini berulang secara mandiri dan kontinu. Osilator ini biasanya merespon proses pemuatan dan pe ngosongan jaringan $R C$ atau $R L$. Osilator ini biasanya membangkitkan isyarat gelombang kotak atau segitiga. Osilator relaksasi dapat merespon aplikasi frekuensi-rendah dengan sangat baik.

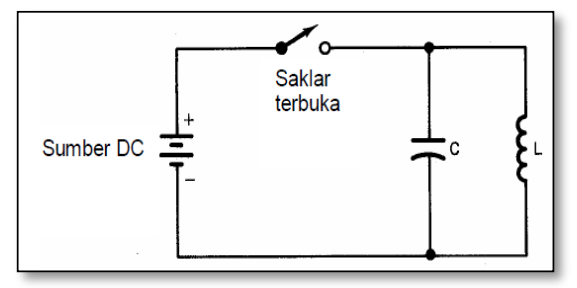

Gambar 4. Rangkaian Dasar Tangki LC

\section{Frekuensi Resonansi}

Berdasarkan rumus resonansi paralel pada LC osilator, yaitu:

$$
f_{1}=\frac{1}{2 \pi \sqrt{L C}}
$$

Maka jika ditambahkan sebuah induktor yang tidak diketahui nilainya $\left(L_{x}\right)$ akan terhubung secara paralel terhadap kapasitor maka perhitungan Lx dapat dirumuskan sebagai berikut:

$L_{x}=\frac{1}{C(2 \pi f)^{2}}$

Dari hasil perumusan resonansi diatas, dapat dipastikan bahwa untuk mendapatkan nilai kapasitor maupun induktor yang ditambahkan, dibutukan harga frekuensi $f$ yang didapat dari panjang gelombang T.

\section{Komparator LM393}

Rangkaian komparator pada umumnya menggunakan sebuah komponen Operasional Amplifier (Op-Amp). Adapun komponen yang akan digunakan untuk alat ukur induktansi digital adalah IC tipe LM393. LM393 merupakan tipe IC yang banyak dipakai untuk keperluan seperti penguat audio, instrumentasi dan rangkaian filter karena kemudahan untuk mendapatkannya serta harganya yang terjangkau.

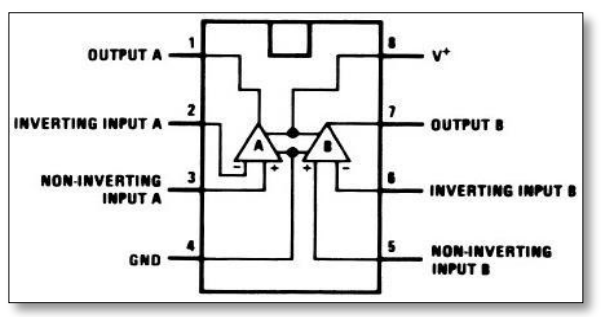

Gambar 5. Konfigurasi Pin ICLM393

Relay

Relai pengendali elektromekanis (an elektromechanical relay = EMR) adalah saklar magnetis. Relai ini menghubungkan rangkaian beban ON atau OFF dengan pemberian energi elektromagnetis, yang membuka atau menutup kontak pada rangkaian. Untuk menggerakan relay, daya (arus/tegangan) dari mikrokontroller kurang mencukupi sehingga perlu penguat (driver).

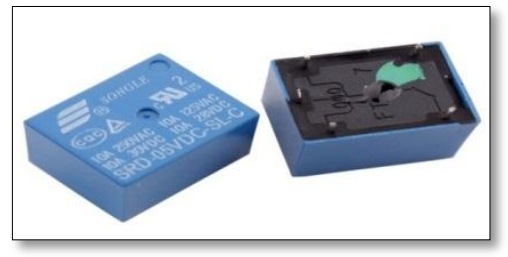

Atmega32

$$
\text { Gambar 6. Relay }
$$

Mikrokontroler merupakan sistem komputer yang seluruh atau sebagian besar elemennya dikemas dalam satu chip IC (Intergrated Circuit) sehingga sering juga disebut single chip microcomputer, yang masuk dalam kategori embedded komputer. Suatu kontroler digunakan untuk mengontrol suatu proses atau aspek-aspek dari lingkungan. 


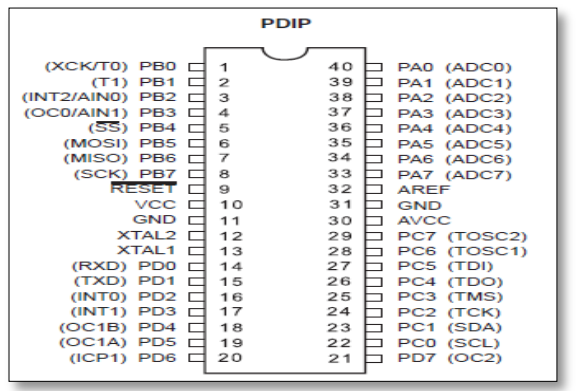

Gambar 7. Konfigurasi Pin Atmega32

CodeVision AVR merupakan sebuah software yang digunakan untuk memprogram mikrokontroler sekarang ini telah umum. Salah satu compiler program yang umum digunakan sekarang ini adalah CodeVision AVR yang menggunakan bahasa pemrograman $\mathrm{C}$.

\section{Display LCD 16x2}

Display LCD 16x2 berfungsi sebagai penampil karakter yang di input melalui keypad. LCD yang digunakan pada alat ini mempunyai lebar display 2 baris 16 kolom atau biasa disebut sebagai LCD Character 16x2, dengan 16 pin konektor, yang didefinisikan sebagai berikut: (Wardhana, Lingga, 2006)

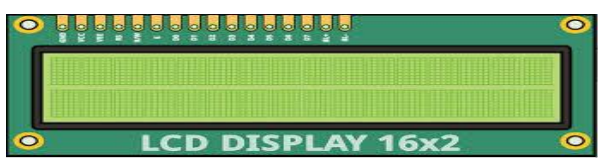

Gambar 8. Pin-pin Antarmuka LCD

\section{PERANCANGAN ALAT}

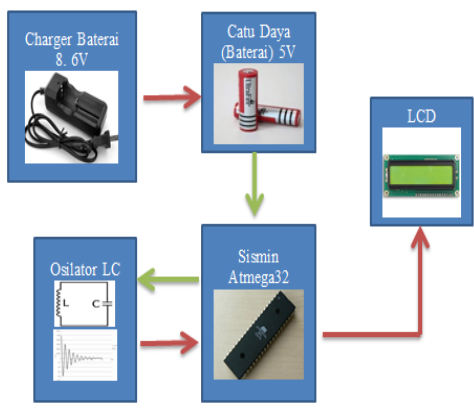

Gambar 9. Blok Diagram Rangkaian Keseluruhan

a. Catu Daya Charger8.6V

Merupakan rangkaian yang berfungsi untuk mensuplai tegangan pada saat tegangan baterai habis. Catu daya ini terdiri dari trafo, dioda, kapasitor, IC LM317.

b. Catu Daya Baterai $8.4 \mathrm{~V}$

Rangkaian yang berfungsi untuk mensuplai tegangan rangkaian. Tegangan ini didapat dari baterai, IC 1M7805 agar tegangan keluaran sesuai dengan tegangan kerjanya.

c. Osilator LC
Rangkaian yang berfungsi sebagai pembangkit frekuensi pada saat mengukur nilai induktansi dari suatu induktor dengan proses osilasi.

d. Komparator IC LM393

Rangkaian osilator LC dilengkapi dengan komparator IC IM393 yang berfungsi agar gelombang yang dihasilkan dapat diubah menjadi gelombang kotak.

e. Sismin Atmega 32

Berfungsi sebagai pengendali yang akan memproses semua input, output, dan menjalankan sistem secara keseluruhan.

f. LCD Display $16 \times 2$

Berfungsi untuk menampilkan pembacaan hasil dari pengukuran /kalkulasi nilai induktansi yang sedang diukur yang tampilannya berupa angka dan huruf.

3.1. Osilator LC

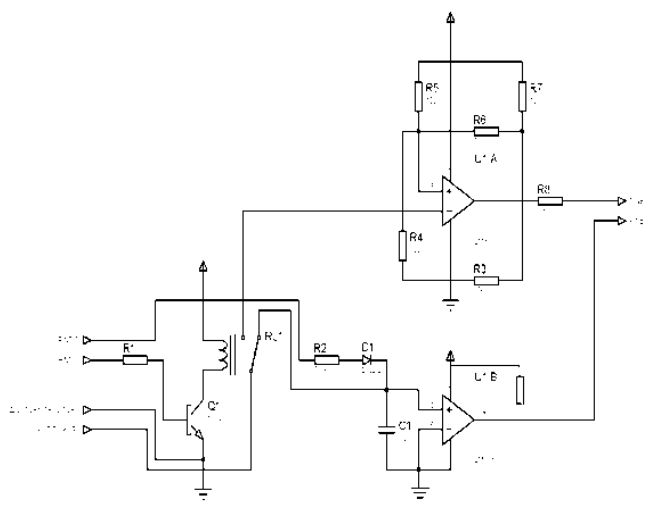

Gambar 10. Rangkaian Osilator LC

Proses atau siklus pergantian pengisian muatan antara induktor yang diukur dengan kapasitor yang dipasang paralel akan menghasilkan keluaran yang berupa gelombang sinyal dan karena arus dan tegangannya perlahan mengecil maka bentuk gelombang juga akan mengecil (osilasi teredam).

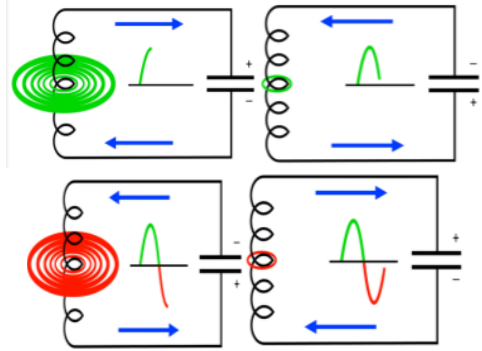

Gambar 11.. Proses Osilasi pada Tangki LC

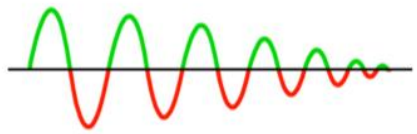

Gambar 12. Gelombang Hasil Osilasi Tangki LC

Merupakan rangkaian driver relay yang menggunakan transistor jenis NPN, dengan cara kerjanya apabila kaki basis transistor tersebut mendapat logic $1(H I G H)$ maka akan mengalir arus dari emitor ke basis yang mengakibatkan transistor 
bekerja, kaki emitor dan kaki kolektor terhubung (aktif $H I G H)$.

\section{Rangkaian Keseluruhan}

Untuk cara kerja dari rangkaian keseluruhan pada alat ukur induktansi digital ini akan dijelaskan sesuai dengan alur dari flowchart kerja rangkaian

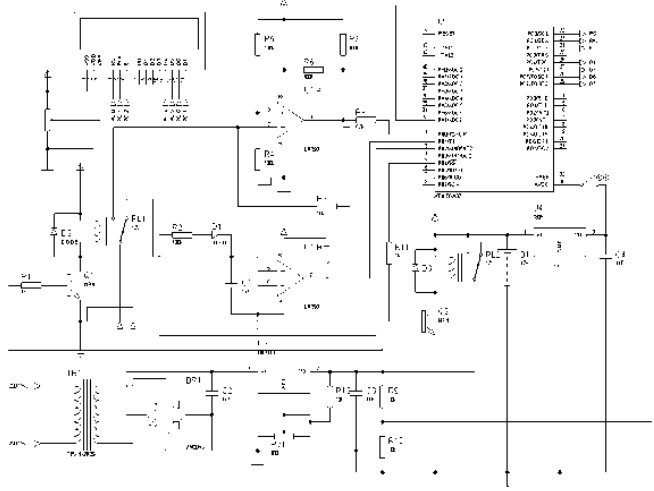

Gambar 13. Rangkaian Keseluruhan

Sesuai dengan rangkaian keseluruhan diatas alat ukur induktansi ini akan bekerja aktif apabila diberi tegangan $5 \mathrm{~V}$ yang berasal dari rangkaian catu daya. Mikrokontroler kemudian akan memberikan sinyal HIGH kepada rangkaian osilator sebagai sinyal trigger agar tangki LC aktif. Arus sinyal yang diberikan oleh mikrokontroler selama $5 \mathrm{~ms}$ akan mengalir ke tangki $L C$ melalui resistor $100 \Omega$ agar arus yang masuk ke rangkaian kecil. Karena mendapat bias maju maka arus ini akan mengalir melewati dioda menuju ke tangki $L C$, fungdi dioda disini agar aliran arus tidak membalik ke sumber pada saat kapasitor discharging. Arus mengalir ke kapasitor $\mathrm{C} 1 \mathrm{uF}$ kemudian kapasitor akan mengalami kenaikan tegangan hingga muatan pada kapsitor terisi penuh charging. Kapasitor akan menyimpan muatan yang berupa medan listrik. Ketika muatan pada kapasitor penuh maka kapasitor akan melepaskan muatannya discharging menuju induktor yang dipasang paralel terhadap kapasitor tersebut. Induktor perlahan mendapat arus yang berasal dari kapasitor yang lama- kelamaan akan membentuk medan magnet. Proses discharging kapasitor ini akan berhenti sampai muatan pada kapasitor tersebut habis. Dan pada kondisi kapasitor tidak memiliki muatan, induktor akan bergantian mensuplai dari medan magnet yang dihasilkan dengan mengalirkan arus ke kapasitor. Muatan induktor berkurang sedangkan muatan pada kapasitor bertambah. Setelah induktor tidak memiliki muatan lagi kapasitor akan mengalirkan arus kembali melakukan pengosongan ke induktor.Siklus ini akan terjadi secara berulang bergantian saling mengisi antara kapasitor dan induktor tetapi perlahan arus dan tegangan yang digunakan besarnya akan mengecil. Maka hasil dari proes tersebut biasanya disebut dengan osilasi teredam dengan keluaranya yang berupa gelombang sinus yang memiliki amplitudo semakin kecil dengan periode yang tetap. Untuk mempermudah dalam pembacaan frekuensi dari gelombang yang dihasilkan oleh tangki LC maka digunakan komparator LM393 agra gelombang sinus dirubah menjadi gelombak kotak. Cara kerja dari komparator disini adalah membandingkan masukan Vin terhadap Vreff. Karena kaki Vreff pada rangkaian dihubungkan dengan ground, maka nilai dari Vreff sendiri adalah $0 \mathrm{~V}$. Jadi pada saat Vin melebihi $0 \mathrm{~V}$ maka keluaran komparator adalah HIGH $5 \mathrm{~V}$ begitupun juga sebaliknya pada saat Vin lebih kecil dari $0 \mathrm{~V}$ maka keluaran komparator akan LOW $0 \mathrm{~V}$. Sehingga dengan adanya keluaran HIGH dan LOW tersebut akan menghasilkan suatu gelombang kotak yang lebih mudah untuk dibaca. Keluran komparator tersebut juga dilengkapi dengan resistor $1 \mathrm{~K}$ yang berfungsi sebagai resistor pull up agar mencegah tejadinya floating. Kemudian gelombang kotak yang telah dihasilkan oleh rangkaian oasilator tersebut akan masuk kedalam sismin Atmega32 untuk diproses melalui PORTB. Mikrokontroler akan membaca berapa frekuensi gelombang tersebut berdasarkan panjang dari gelombang. Panjang gelombang ini akan dikonversi dengan menggunkan rumus secara matematis $f=1 / T$. Setelah diketahui nilai frekuensi gelombang maka mikrokontroler akan mengkalkulasi nilai induktansi dari induktor yang diukur sesuai rumus frekuensi reonansi. Hasil keluaran proses yang terdapat di mikrokontroler kemudian akan ditampilkan di LCD.

\section{PENGUJIAN DAN ANALISA}

Pengukuran induktansi induktor dengan menggunakan pengukuran sesuai perhitungan dengan menggunakan rumus resonansi frekuensi.

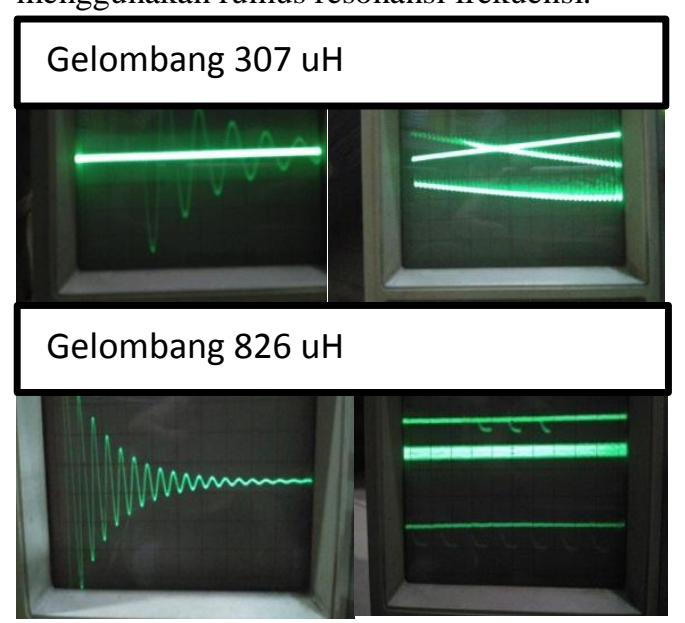

Gambar 14. Pengukuran Gelombang dengan Osiloskop 
Tabel 1. Hasil pengukuran induktansi dengan menggunkan perhitungan

\begin{tabular}{ccc}
\hline Frekuensi $(\mathrm{Hz})$ & $\begin{array}{c}\text { Hasil } \\
\text { Pengukuran } \\
(\mu \mathrm{H})\end{array}$ & $\begin{array}{c}\text { Hasil } \\
\text { Perhitungan } \\
(\mu \mathrm{H})\end{array}$ \\
\hline 27777 & 34,2 & 32,86 \\
19230 & 71,35 & 68,56 \\
18518 & 76,95 & 73,94 \\
17857 & 82,75 & 79,51 \\
12500 & 168,87 & 162,27 \\
\hline
\end{tabular}

Dari data percobaan datas yaitu antara data hasil pengukuran Induktor yang ditampilkan di display LCD hasilnya sesuai dengan nilai induktansi yang didapat dengan menggunakan perhitungan.

Tabel 2. Pengukuran Induktansi untuk Ratio Kesalahan.

\begin{tabular}{|c|c|c|c|c|}
\hline $\begin{array}{c}\text { Kode } \\
(\mu \mathrm{H})\end{array}$ & $\begin{array}{c}\text { LCR } \\
\text { Std } \\
(\mu \mathrm{H})\end{array}$ & $\begin{array}{c}\text { Hasil } \\
\text { baca } \\
\text { alat } \\
(\mu \mathrm{H})\end{array}$ & $\begin{array}{c}\text { error } \\
\text { terhadap } \\
\text { kode } \\
\text { warna } \\
(\%)\end{array}$ & $\begin{array}{c}\text { error } \\
\text { terhadap } \\
\text { LCR std } \\
(\%)\end{array}$ \\
\hline 33 & 32,9 & 34,2 & $3,9 \%$ & $0,3 \%$ \\
\hline 68 & 68,8 & 71,35 & $6,8 \%$ & $1,7 \%$ \\
\hline 82 & 78,2 & 82,75 & $5,8 \%$ & $4,6 \%$ \\
\hline 220 & 190 & 195,18 & 2,7 & 35,4 \\
\hline 330 & 275 & 319,35 & 16,1 & 16,6 \\
\hline
\end{tabular}

\section{PENUTUP}

Setelah melakukan perancangan, pembuatan benda kerja dan percobaan, maka dapat diperoleh beberapa kesimpulan sebagai berikut :

1. Daerah pengukuran atau level yang dapat menggunakan alat ukur ini adalah nilai induktansi antara $20 \mu \mathrm{H}-100 \mathrm{mH}$.

2. Alat ukur induktansi menggunkan osilator $L C$ untuk membangkitkan frekuensi sehingga menghasilkan frekuensi resonansi pada saat pengukuran Induktor dan menggunakan Atmega32 sebagai sistem kontrolnya.

3. Display LCD $16 \times 2$ sebagai media penampil hasil pengolahan data yang sudah diolah dan diproses dari Atmega32 yang menunjukan nilai induktansi dalam Henry $(u H, m H)$ dengan frekuensi yang dibangkitkan atau diperoleh dari rangkaian osilator LC.
4. Dari hasil analisa data dapat diperoleh bahwa nilai induktansi yang diukur dibandingkan dengan hasil LCR meter standar memiliki linerietas alat yang cukup baik.

5. Nilai rata-rata kesalahan pada saat dilakukan pengkuran induktansi terhadap LCR meter adalah $6.5 \%$

Guna melengkapi kesempurnaan alat ini maka kami sarankan sebagai berikut:

1. Ketelitian alat pengukur ini dapat ditingkatkan dengan penggunaan komponen-komponen yang toleransi ketelitiannya yang cukup tinggi.

2. Sistem ini masih bisa dikembangkan lagi dengan menggunakan rangkaian osilator yang nilai kapasitor dapat diganti dengan beberapa nilai sehingga memperoleh daerah pengukuran yang lebih bervariasi.

3. Alat ini merupakan sistem berbasis mikrokontroler maka diperlukan perawatan dan pengecekan berkala agar kerja alat tetap optimal.

DAFTAR PUSTAKA

1. Mimail,B. (2011) Dasar Teknik Elektro Rangkaian Listrik. Malang UB Press.

2. Malvino, A.P. (1979). Prinsip-Prinsip Elektronik Edisi Kedua (terjemahan Hanapi Gunawan). Jakarta:Erlangga.

3. Malvino, A.P. (1996). Prinsip-Prinsip Dasar Elektronika Edisi Ketiga (terjemahan Prof. M. Barmawi, Ph.D. , M.O. Tjia, Ph.D., Departemen Fisika, Institut Teknlogi Bandung). Jakarta: Erlangga.

4. Bishop, O. (2004). Dasar-Dasar Elektronika (terjemahan Irzam Harmein S.T). Jakarta: Erlangga.

5. Yuliana, E. (2006). Rancang Bangun Alat Induktansi dan Kapasitansi Meter. Semarang. Universitas Negeri Semarang.

6. Amallia, F. (2009). Rancang Bangun Kapasitansi dan Induktansi Meter Menggunakan Mikrokontroler Atmega8 Dengan Tampilan LCD. Jakarta. Universitas Mercu Buana.

7. Frank D, Petrezuella. (2001). Elektronika Industri. Yogyakarta: Andi 